\title{
Measuring positive health of Iranians; Finding from Iran social health survey (ISHS)
}

\author{
Kambiz Abachizadeh ${ }^{1}$, Soheila Omidnia*2, Ahmad Hajebi ${ }^{3}$, Reza Shekarriz-Foumani ${ }^{4}$, \\ Maryam Mohseny ${ }^{4}$
}

Received: 10 Aug 2017

Published: 28 July 2018

\begin{abstract}
Background: Positive health as a "health asset" goes beyond risk factors for diseases and produces longer and healthier life, as well as, better prognosis when illness strikes, against traditional medicine focusing on treating people in negative health to a state that is neutral or free from disease. The aim of present study was to conduct a national survey estimating positive health indicators of Iranians

Methods: This survey was performed on September 2014 in all provinces of Iran with 10500 samples. The psychometrics of employed scale was examined in separate study. To estimate positive health indicators, each question included a series of declarative statements and each respondents answer to questions based on a five-point Likert type scale.

Results: From a total of 10500 respondents, 10244 fulfilled questionnaire (Response rate $=97.5 \%$ ). About $49 \%$ of participants were male. In a scale from 1 to 5 , mean of score of life satisfaction, happiness, quality of life, and self-perceived health were $3.45,3.28,3.56$ and 3.66, respectively. The highest level of positive health indicators was achieved in provinces of Guilan and West Azerbaijan.

Conclusion: The result of the study shows majority of Iranian people assess their perception of health, quality of life, life satisfaction and happiness as 'moderate' or 'good' (between 66 to $82 \%$ of respondents. It would seem that measured positive health indicators in comparison with the rates of past national studies, have been decreased between 3.5 to $4 \%$ that should be noticed in social health policy making.
\end{abstract}

Keywords: Positive health, Iran, Indicator, Survey, National

Copyright@ Iran University of Medical Sciences

Cite this article as: Abachizadeh K, Omidnia S, Hajebi A, Shekarriz-Foumani R, Mohseny M. Measuring positive health of Iranians; Finding from Iran social health survey (ISHS). Med J Islam Repub Iran. 2018 (28 July);32:63. https://doi.org/10.14196/mjiri.32.63

\section{Introduction}

Based on definition of world health organization (WHO), health is defined as "individual well-being in three dimensions; physical, mental and social- not merely absence of illness" (1). This revolutionary definition has changed our view on health from "negative health" which focuses on diseases to "positive health" as a new dynamic concept based on better quality of life. Similar changes have been occurred in other branches of human science in that positive psychology has been emerged in past decades $(2,3)$. Positive health as a "health asset" goes beyond risk

Corresponding author: Soheila Omidnia, ne_soha@yahoo.com

1. Social Determinants of Health Research Center, Shahid Beheshti University of Medical Sciences, Tehran, Iran, \& Department of community medicine, School of Medicine, Shahid Beheshti University of Medical Sciences, Tehran, Iran.

2. Social Health Office, Health Deputy of Ministry of Health and Medical Education, Tehran, Iran.

3. Research Center for Addiction \& Risky Behaviors (ReCARB), Psychiatric Department, Iran University of Medical Sciences, Tehran, Iran.

${ }^{4}$. Department of Community Medicine, School of Medicine, Shahid Beheshti University of Medical Sciences, Tehran, Iran. factors for diseases and produces longer and healthier life, as well as, better prognosis when illness strikes, against traditional medicine focusing on treating people in negative health to a state that is neutral or free from disease (4). Positive health is even beyond the prevention that identifies a hazardous factor with the aim of alleviating risk, while positive health establishes capacities to improve health (5). Building positive health may prevent future diseases with the goal of establishing a flourishing life (6).

\section{$\uparrow$ What is "already known" in this topic:}

Few national studies has been conducted in Iran towards positive health indicators which could be used as a good instrument in hands of national level policy makers to monitor main social and health trends.

\section{$\rightarrow$ What this article adds:}

Lower level of Iranians' positive health indicators in comparison to majority of developed countries. Assessing estimates of recent study with similar national studies which has been conducted in past five years (before 2014) demonstrates a slight decrease in positive health indicators. 
Following the definition of WHO, different aspects of positive health, such as life satisfaction, quality of life, happiness and self-rated health has been argued for decades and subsequent attempts were made to develop appropriate scales applicable to measure positive health (710). Initial efforts were directed to measure positive health in limited clinical setting. Then, studies expand to larger populations- a city or province and next to national and regional, even global level. World happiness study conducted by United Nations, Social Survey by European Union, and a number of national social surveys such as Irish, Welsh, New Zealand are good illustrations of such studies $(11,12)$. In a number of countries, assessing positive health indicators are a part of national health survey alongside with other aspects such as physical health and risky behaviors $(12,13)$.

Positive health indicators are going to be one of the main pre-requirements of social policy-making despite inadequate attention in present medicine. A large number of documents shows that the people with higher level of positive health, are more likely to be healthier both now and later, and more productive (14-16).

Consequently the trend of positive indicators would be a valuable instrument for policy-makers of different sectorsnot merely health sector to make best decisions ${ }^{16}$. In fact, positive health indicators represent how several sectors interact with each other allowing us to monitor well-being of the community in an effective way $(17,18)$.

In Iran, a large number of studies have been conducted towards measuring positive health indicators, particularly quality of life in clinical setting and for different groups of patients (19-24), also a national electronic bank of scales measuring quality of life has been developed by the institute of 'health science studies of Jihad-Daneshgahi'(25). But, to our knowledge and search, no national study has been conducted to assess different aspects of positive and social health in Iran in past 5 years. Therefore, the survey of Iranian national social health with an emphasis on different areas of positive and social health were conducted with a population-based approach in September 2014 led by "social health office" of Ministry of Health in collaboration with Shahid Beheshti University of Medical Sciences. This manuscript represents some findings of conducted 'survey of Iranian national social health".

\section{Methods}

Iran social health survey (ISHS) was conducted in a cross-sectional approach in all 31 provinces on September 2014 with a total of 10500 participants who were aged more than 18 years old.

\section{Data}

Sample size was calculated based on estimates of previously conducted studies and with clustering effect and predicted non-response rate. Proportion to size approach was employed to determine sample of each province considering that the sample size in each province should not be less than 230 to assure adequate accuracy of estimates in provincial level. Stratified sampling approach was employed in each province. Three strata were considered as; 'center of the province'; 'cities other than center of province with more than 20000 populations'; and a 'rural area' with sample size of 5900, 3200, and 3900, respectively which were proportional to size. Definition and divisions of Iran Ministry of State was used for city and rural area. Samples were achieved from center of province, a randomly selected city other than center of province and a randomly selected rural area of each province.

To select samples in households, map of blocks for each city and rural area was used, and a random sample drawn from blocks enumerated on a map. A field interviewer visited the selected blocks stating at the bottom and left side of the block and circling clockwise to estimate the number of households. The size of each cluster was considered as 10 . Therefore, the estimated household number in each block was divided into 10 to achieve 'sampling interval'. The household at the bottom and left of the block was selected as first sample and the next household determined based on the number of previously selected household plus 'sampling interval'. Quota method was employed to select an individual in a household. Interviewers completed the sample in cluster based on a table which displayed the age and sex distribution in the enumeration area based on the reports of national statistics organization.

Since ISPA (Iranian Students Polling Agency) is a professional organization in conducting field surveys, therefore, pre-prepared sampling framework and maps were used.

323 professional interviewers contributed to gather the data. To control inter-rater bias, coordinated meeting was organized by project manager and provincial executive officer. Next, similar meetings were held in all provinces.

\section{Variables}

Demographic characteristics such as age, sex, educational level, occupation, marital status, and location of participants were recorded.

Four Positive health indicators including self-perceived 'health status', 'happiness', 'quality of life', 'life satisfaction' were assessed using single questions. For example, 'selfperceived health status was assessed by the following question': 'How is your health in general' along with a 5item likert-type scale answer containing 'very bad', 'bad', 'fair', 'good', and 'very good'. To quantifying the variable, items were scored by assigning a value of five for "very good" to one for "very bad". Self-rated scales are wellknown and widely accepted indicators to evaluate positive health indicators in national and international level (26,). Using single questions to evaluate such indicators has been recommended by WHO and Euro-REVES as valuable instrument with acceptable psychometrics. Validity and reliability of these single questions has been checked and reported in the work of Montazeri as 'Iranian Health Perception Survey' (27).

Self-rated social health was assessed in this survey using a 33-item scale but the related analysis have not been presented in this manuscript and the focus of recent work is only on 'Self-perceived health status', 'happiness', 'quality of life', 'life satisfaction'. 
Scale utilized to assess positive health was examined in terms of face validity through representing to citizens participated in pilot study, confirmed the clarity and simplicity of questions and to five experts to ensure content validity. The reliability was assessed through a 100-sample testretest study. The ICC (Intra-class correlation) was between $0.68-0.75$ for 4 scales. Criterion validity of scales with a 40 -questioned national happiness scale was examined. The correlation coefficient of scales with 40-item happiness scale as a gold standard was between $0.49,0.53$, 0.570 .60 for 'health status', 'happiness', 'quality of life', 'life satisfaction', respectively.

To fulfill questionnaire, the method was primarily explained to respondents then they filled out forms by themselves. The items were completely read for illiterates. Participants informed their consent verbally. Each question included a series of declarative statements answered based on a five-point Likert type scale. All interviewers were professional with adequate experience in previous similar surveys, and trained for administer interview. Attempts were made to harmonize interview approach to minimize intra-rater error. It should be noticed that the interview phase of study was performed by ISPA (Iranian Students Polling Agency), a well-established and functioning institute with valuable experience in conducting social surveys.

\section{Statistical analysis}

To analyze data, the descriptive statistics were employed to show the key features of samples. Twoindependent sample t-test was employed to compare positive health between males and females and One-Way ANOVA to compare different age groups considering LSD post-hoc test.

\section{Results}

In this study, 10244 participants from a total of 10500 samples fulfilled questionnaire (Response rate was $97.5 \%$ ). of which $39 \%, 33 \%, 20 \%$ and $8 \%$ were between $18-30,31-45,46-60$, and more than 65 years old, respectively. The mean and standard deviation of participants' age were 37.9 and 14.3 respectively. Also, 5240 (49.2\%) were male and $5040(50.8 \%)$ were female. Table 1 shows the demographic characteristics of respondents.

Figure 1 shows the error bar representing the mean and $95 \%$ confidence interval of four positive health indicators. Obtained values were compared with estimates of previously conducted similar national surveys to portray the trend of indicators in 'discussion' part of the manuscript.

Table 2 displays the number and percent of each category. As it is shown from the tables, in the area of life satisfaction and happiness, the category of 'moderate' and in the area of 'quality of life' and 'self-rated health', the category of 'good' include the highest number of people.

\begin{tabular}{lcc} 
Table 1. Demographic characteristics of respondents \\
\hline Variables & Subgroups & $\begin{array}{c}\text { Number } \\
\text { (percent) }\end{array}$ \\
\hline sex & Male & $5040(49 \%)$ \\
Age(year) & Female & $5240(51 \%)$ \\
& $18-30$ & $3998(39 \%)$ \\
& $31-45$ & $3392(33 \%)$ \\
Educational & $46-60$ & $2071(20 \%)$ \\
status & No formal education & $766(8 \%)$ \\
& A degree lower than diploma & $1141(15 \%)$ \\
Location & Diploma degree & $3124(42 \%)$ \\
& University degree & $101(1 \%)$ \\
& City (Center of province) & $5413(53 \%)$ \\
City (other than Center of & $1623(16 \%)$ \\
Sccupational & province) & \\
& Rural areas & $3208(31 \%)$ \\
& Employed & $4139(41 \%)$ \\
& Housewife & $3489(34 \%)$ \\
Marital status & Student & $1012(10 \%)$ \\
& Retired & $590(6 \%)$ \\
& Single- never married & $2462(24 \%)$ \\
& Divorced & $222(2 \%)$ \\
& Widow & $429(4 \%)$ \\
& married & $7045(69 \%)$ \\
\hline
\end{tabular}

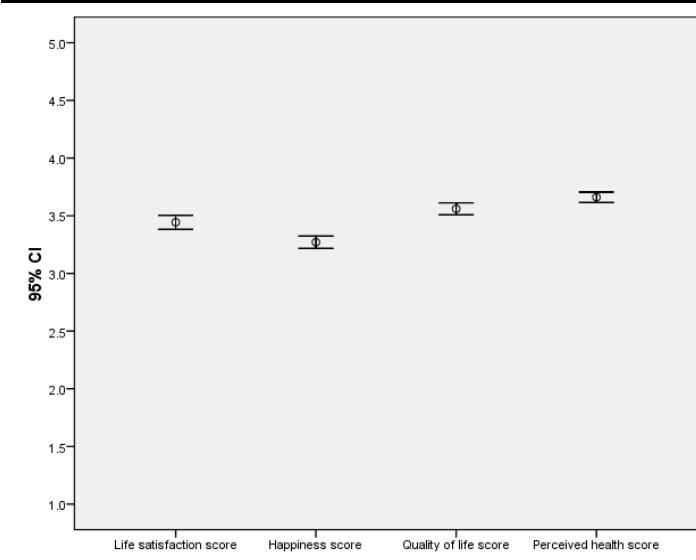

Fig. 1. Mean and $95 \% \mathrm{CI}$ of four positive health indicators

Table 3 shows the situation of each province in positive health indicators. Each row shows the rank of each province among 31 provinces and the mean score of positive health indicators. As it could be seen from the figures, Guilan as a northern provinces is one of three top ranks in the area of life satisfaction, happiness and quality of life. Similarly, west Azerbaijan is one of three top ranks in the area of life satisfaction, happiness and self-perceived health. The rank of Tehran province including Tehran city as capital among 31 provinces is $13,12,19,13$ in the area of life satisfaction, happiness, quality of life, and selfperceived health, respectively. Province of Ardebil places in the last rank in three of four areas of positive health.

The relationship between gender and four positive health indicators was also examined. While the score of life satisfaction and quality of life was a little higher in

Table 2. Distribution of participants in different categories of four positive health indicators.

\begin{tabular}{|c|c|c|c|c|c|}
\hline Indicators & $\begin{array}{c}\text { Very poor } \\
N(\%)\end{array}$ & $\begin{array}{l}\text { Poor } \\
\text { N (\%) }\end{array}$ & $\begin{array}{c}\text { Moderate } \\
\text { N (\%) }\end{array}$ & $\begin{array}{l}\text { Good } \\
\text { N (\%) }\end{array}$ & $\begin{array}{c}\text { Very good } \\
\mathrm{N}(\%)\end{array}$ \\
\hline Life satisfaction & $659(6.6)$ & $943(9.4)$ & $3379(33.6)$ & $3305(32.9)$ & $1172(17.6)$ \\
\hline Happiness & $868(8.7)$ & $1151(11.5)$ & $3729(37.2)$ & $2845(28.4)$ & $1429(14.3)$ \\
\hline Quality of Life & $259(2.6)$ & $402(4.0)$ & $3976(39.5)$ & $4291(42.6)$ & $1141(11.3)$ \\
\hline Self-rated Health & $245(2.4)$ & $604(6.0)$ & $3095(30.8)$ & $4479(44.5)$ & $1636(16.3)$ \\
\hline
\end{tabular}


Table 3. Situation of each province among 31 provinces in four positive health indicators

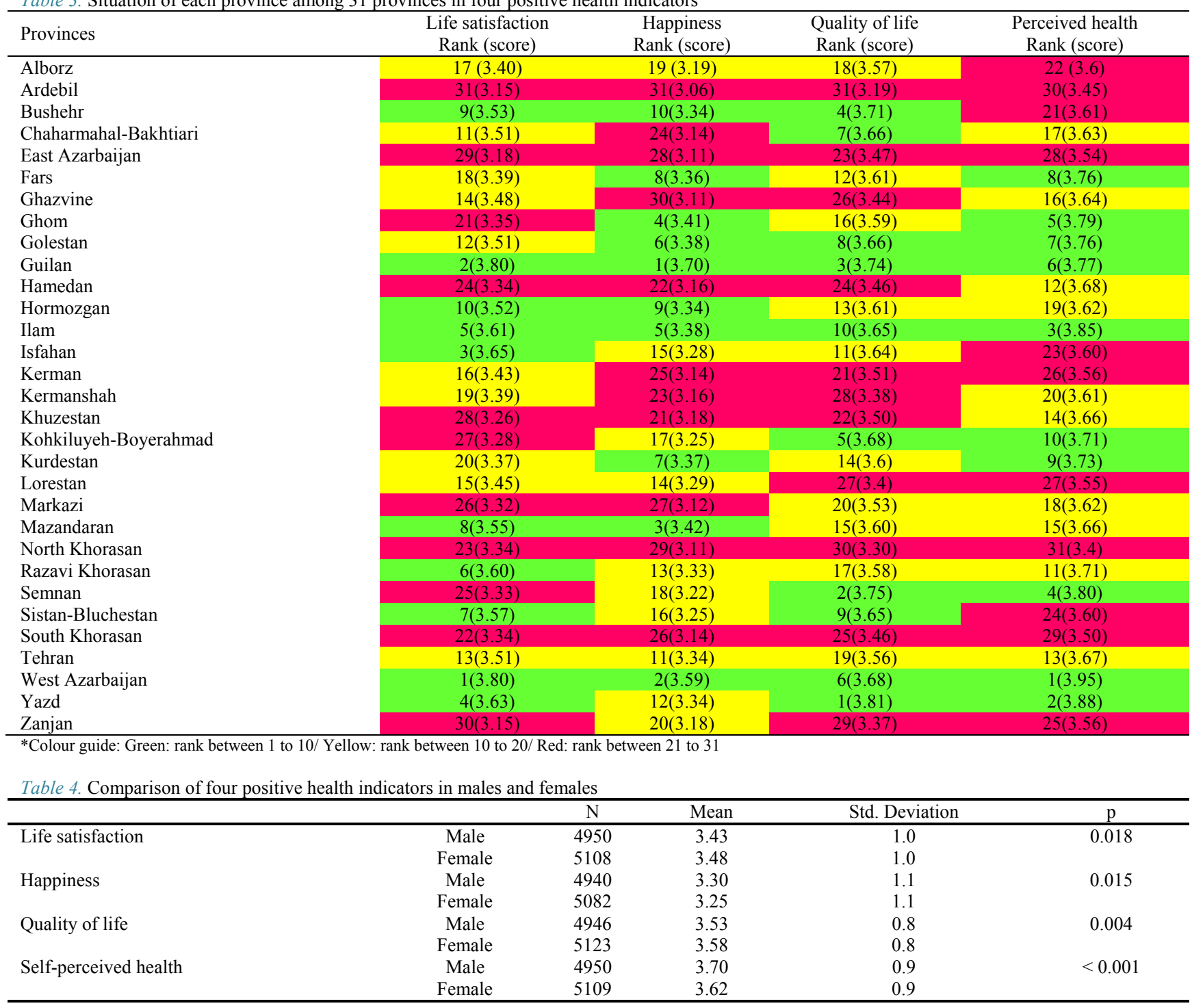

females $(\mathrm{p}<0.05)$, but happiness and self-perceived health scores were higher in males $(\mathrm{p}<0.05)$ that are displayed in detail in Table 4.

Moreover the relationship between age and positive health was examined after categorization of respondents' age but no significant relationship found between age and life satisfaction. While in the case of happiness, quality of life and self-perceived health, showed to have downward trend. With rise in ages, the score for three indicators was reduced (Table 5)

Association of other demographics and positive health indicators is summarized as follows:

\begin{tabular}{|c|c|c|c|c|c|c|c|}
\hline & & \multirow[t]{2}{*}{$\mathrm{N}$} & \multirow[t]{2}{*}{ Mean } & \multirow[t]{2}{*}{ Std. Deviation } & \multicolumn{2}{|c|}{ 95\% Confidence Interval for Mean } & \multirow[b]{2}{*}{$\mathrm{p}$} \\
\hline \multirow{3}{*}{ Life satisfaction } & & & & & Lower Bound & Upper Bound & \\
\hline & $18-30$ & 3909 & 3.46 & 1.12 & 3.43 & 3.50 & 0.281 \\
\hline & $31-45$ & 3337 & 3.47 & 1.08 & 3.44 & 3.51 & \\
\hline \multirow{5}{*}{ Happiness } & $46-60$ & 2041 & 3.42 & 1.04 & 3.37 & 3.46 & \\
\hline & $60<$ & 755 & 3.47 & 1.05 & 3.40 & 3.55 & \\
\hline & $18-30$ & 3901 & 3.36 & 1.14 & 3.32 & 3.40 & $<0.001$ \\
\hline & $31-45$ & 3320 & 3.25 & 1.10 & 3.21 & 3.28 & \\
\hline & $46-60$ & 2036 & 3.22 & 1.07 & 3.18 & 3.27 & \\
\hline \multirow{3}{*}{ Quality of life } & $60<$ & 750 & 3.20 & 1.09 & 3.12 & 3.28 & \\
\hline & $18-30$ & 3929 & 3.64 & 0.87 & 3.61 & 3.67 & $<0.001$ \\
\hline & $31-45$ & 3324 & 3.55 & 0.82 & 3.53 & 3.58 & \\
\hline \multirow{6}{*}{ Self-perceived health } & $46-60$ & 2042 & 3.47 & 0.81 & 3.44 & 3.51 & \\
\hline & $60<$ & 758 & 3.44 & 0.83 & 3.38 & 3.50 & \\
\hline & $18-30$ & 3923 & 3.89 & 0.85 & 3.86 & 3.92 & $<0.001$ \\
\hline & $31-45$ & 3321 & 3.66 & 0.85 & 3.63 & 3.69 & \\
\hline & $46-60$ & 2042 & 3.43 & 0.91 & 3.39 & 3.47 & \\
\hline & $60<$ & 758 & 3.11 & 0.98 & 3.04 & 3.18 & \\
\hline
\end{tabular}


- Location: 'quality of life', 'happiness', and life satisfaction was significantly higher in 'cities other than center of provinces' in comparison to 'center of provinces' and rural areas.

- Marital status: all four positive health indicators were significantly higher at the $\mathrm{P}$ Value $=0.05$ level in the group of people who were never-married or married' in comparison to those divorced or widow.

- Educational level: all four indicators were high in people with academic education in comparison to others.

- Employment: all four indicators were lower in unemployed people in comparison to others.

The correlation between four positive health indicators was examined. All correlations were significant at the $\mathrm{p}=0.05$ level and correlation coefficient was ranged from 0.59 (between life satisfaction and self-rated health status) to 0.74 (between quality of life and self-rated health status).

\section{Discussion}

The result of the study shows majority of Iranian people assess their perception of health, quality of life, life satisfaction and happiness as 'moderate' or 'good' (between 66 to $82 \%$ of respondents); A lower number as 'very good'; and finally a minority as 'poor' or 'very poor'. At first view, it seems the status of positive health indicators according to assignment of people in five ordered groups is approximately desirable. Since the percentage of people in group "very good" and "good" was higher than people in group "poor " and "very poor", While in comparison with other countries, the situation is worse than majority of developed countries. For example, results of SLAN (Survey of Lifestyle, Attitudes, and Nutrition, 2007, Ireland) indicate that $90 \%$ of respondents rate their quality of life as 'good' or 'very good' (13).

We assessed the trend of positive social health indicators through comparison the results of our study with similar researches that has been conducted in preceding 5 years. Given that there is no national comprehensive study of social and positive indicators, we use studies which assess some dimensions of positive health with similar methods. In terms of life satisfaction, the amount of this indicator in a scale from 1 to 5 has been changed from 3.61 in 2006 to 3.45 in 2014 (adjusted percentage of change $=4 \%$ reduction). The later study in 2006 had been conducted with a total sample of 12000 from general population using a single-term question to estimate life satisfaction (28). Self- rated health has been 3.80 in 2009 resulted from a national survey with a total of 28000 participants (27), that changed to 3.66 in 2014 (our study) indicating $3.5 \%$ decrease. With regard to happiness, there is a 3.7 percentage reduction from 3.43 in 2009 to 3.28 in 2014 (29). We did not find any study with similar method related to quality of life to our study. In brief, it seems that there is a slight decreasing trend of positive health indicators.

Study finding shows that there is no significant gender inequity in that in terms of life satisfaction and quality of life, female scores are a little higher but scores of happi- ness and self-perceived health are a little less. It seems that the reasons are rooted in increasing educational level and social participation of Iranian females in recent years and consistent with other studies (31). In Addition, assessing positive health indicators in different age groups represents the fact that no significant relationship exist between age group and life satisfaction. But there is a downward trend of quality of life, happiness and selfperceived health when individual age increases indication moves toward special attention to the elderly people. While comparison with other studies, this feature is consistent, especially regarding to the area of quality of life and self-perceived health. However, according to other studies, higher age is associated with higher level of life satisfaction and happiness because of probable lower expectations. Furthermore, there is no special geographical pattern of positive health and not consistent with socioeconomic status of provinces indicating that positive health is a complex concept could not be simply predicted based on general social indicators such as income level.

In our study, we use single-item scale to assess different positive health indicators that are valid and reliable enough to estimate them with acceptable precision (31). A majority of national and regional surveys have been conducted in similar way. An example of such single-item scale includes: "All things considered, how satisfied are you with your life?" to minimize the time required, particularly in large national surveys. In addition, a number of studies have indicated that short-form scales are beneficial to predict individuals' future health status and probability of diseases and death. In brief, due to limitations of field studies, using mentioned scales are an efficient and valuable way to study positive health.

As resulted from our study, correlation coefficient between four indicators of positive health is between 0.36 and 0.63 indicating that in spite of considerable correlation between these indicators, all of them are required to make a clear portray of community positive health. It would seem that each indicator shows sole entity of positive health that could not be alternate with another one.

It would appear that measuring positive health indicators is a good instrument to monitor effect of grand social trends and interventions (14). European Union social wellbeing survey conducted in 6 rounds, by 2012 is a good illustration that utilize positive health indicators to monitor overall social well-being of Europeans that takes place every two years (11). To achieve this aim, considering more limited resources in Iran, we recommend conducting the next round of social health survey after 3-5 years, since social trends are not sensitive enough to be detected through annual surveys.

\section{Conclusion}

Positive health indicators are one of the main prerequirements of social policy-making. The result of the study shows majority of Iranian people assess their perception of health, quality of life, life satisfaction and happiness as 'moderate' or 'good'. However, it seems that measured positive health indicators in comparison with the rates of past national studies, have been decreased between 3.5 to $4 \%$. This study can be 
used in evaluating the impact of social policies and providing a fundamental for evidence-based policymaking.

\section{Acknowledgement}

The authors would thank people who contributed in this national project, Social Health Department of Ministry of Health and both ISPA (Iranian Students Polling Agency) and Shahid Beheshti University of Medical Sciences for executive support. Grant for the ISHS was awarded by the Mental and social health department of Ministry of Health and Shahid Beheshti University of Medical Sciences on the approval of the study protocol by the research ethics Committee of university.

\section{Conflict of Interests}

The authors declare that they have no competing interests.

\section{References}

1. Law I, Widdows H. Conceptualising health: insights from the capability approach. Health Care Anal. 2008 Dec 1;16(4):303-14.

2. Helliwell JF, Layard R, Sachs J. (Eds.). World happiness report. New York: Earth Institute, 2012

3. Veenhoven R. Happiness. Encyclopedia of Quality of Life and WellBeing Research. 2014:2637-41.

4. Wallace RB, Kohatsu N. Public health \& preventive medicine (Maxcy- Rosenau- last). 15 ${ }^{\text {th }}$ ed. Mc Graw- Hill, New York. 2006. 3948.

5. Seligman ME. Positive health. Appl Psychol. 2008 Jul 1;57(s1):3-18.

6. Hills P, Argyle M. The Oxford Happiness Questionnaire: a compact scale for the measurement of psychological well-being . Pers Individ Dif. 2002.;33: 1073-1082.

7. Van Lente E, Barry MM, Molcho M, Morgan K, Watson D, Harrington J, McGee H. Measuring population mental health and social wellbeing. Int J Public Health. 2012 Apr 1;57(2):421-30.

8. Hahn EA, Cella D, Bode RK, Hanrahan RT. Measuring social wellbeing in people with chronic illness. Soc Indic Res. 2010 May 1;96(3):381-401.

9. OECD Better Life Initiative. OECD guidelines on measuring subjective well-being. 2013.

10. Diener E, Wirtz D, Tov W, Kim-Prieto C, Choi DW, Oishi S, Biswas-Diener R. New well-being measures: Short scales to assess flourishing and positive and negative feelings. Soc Indic Res. 2010 Jun 1;97(2):143-56.

11. European Social Survey. ESS Round 7 Source Questionnaire. London: ESS ERIC Headquarters, Centre for Comparative Social Surveys, City University London. 2014.

12. Pega F, Valentine N, Matheson D. Monitoring Social Well-being: the case of New Zealand's Social Reports / Te Pūrongo Oranga Tangata. Social Determinants of Health Discussion Paper 3 (Case Studies). 2012.

13. Barry MM, Van Lente, E, Molcho M, Morgan K, McGee H, Conroy RM, WatsonD, Shelley E, Perry I. SLÁN 2007: Survey of Lifestyle, Attitudes and Nutrition in Ireland. Mental Health and Social Wellbeing Report, Department of Health and Children. Dublin: The Stationery Office. 2009.

14. Zaboli R, Seyedin SH, Malmoon Z. Macroeconomic policies and increasing social-health inequality in Iran. Int $\mathrm{J}$ health policy manag. 2014 Aug;3(3):129.

15. Stoll L, Michaelson J, Seaford C. Well-being evidence for policy: A review. London: new economics foundation. 2012 Aug; 10.

16. Thompson S, Marks N. Measuring well-being in policy: issues and applications. Report commissioned by the Foresight Project on Mental Capital and Well-being, Government Office for Science. 2008.

17. Parrish RG. Measuring population health outcomes. Prev Chronic Dis,2010;7(4):A71. http://www.cdc.gov/pcd/issues/2010/jul/10_0005. htm.Accessed [1.5.2015].

18. Abachizadeh K, Tayefi B, Nasehi AA, Memaryan N, Rassouli M, Omidnia S, Bagherzadeh L. Development of a scale for measuring social health of Iranians living in three big cities. Med J Islam Repub Iran. 2014;28:2.

19. Sharifi K, Sooky Z, Tagharrobi Z, Akbari H. Happiness and its related factors among the students of Kashan university of medical sciences in 2006-7. Feyz. 2010 Apr 15;14(1):62-9.

20. Siamian H, Naeimi OB, Shahrabi A, Hassanzadeh R, Abazari MR, Khademloo M, Javadian Koutenaee M. The status of happiness and its association with demographic variables among the paramedical students. Majallahi Danishgahi Ulumi Pizishkii Mazandaran. 2012 Feb 15;21(86):159-66.

21. Babaei H, Zomorrodian AH, Gill SS, Ahmad N, Falahati L. Social Capital and Human Development: A Meta-Analysis in Iran. J Am Sci. 2011;7(6):194-7.

22. Siahpush M, Spittal M, Singh GK. Happiness and life satisfaction prospectively predict self-rated health, physical health, and the presence of limiting, long-term health conditions. Am J Health Promot. 2008 Sep;23(1):18-26.

23. Nejati V, Shirinbayan P, Akbari Kamrani A, Foroughan M, Taheri $\mathrm{P}$, Sheikhvatan M. Quality of life in elderly people in Kashan, Iran. Middle East J Age Aging. 2008;5(2):21-5.

24. Mohamadi K, Ahmadi K, Ashtiani AF, Fallah PA, Ebadi A, Yahaghi E. Indicators of Mental Health in Various Iranian Populations. Iran Red Crescent Med J. 2014 Feb;16(2).

25 . Bank of scales of measuring health. Health scinces research center of Jihad-Daneshgahi (n.d.). Retrieved July 15, 2017, http://www.qolbank.ir/Fa/default.aspx.

26. Bardage C, Pluijm SM, Pedersen NL, Deeg DJ, Jylhä M, Noale M, Blumstein T, Otero Á. Self-rated health among older adults: a crossnational comparison. Eur J Ageing. 2005 Jun 1;2(2):149-58.

27. Vahdani-nia MS, Ebadi M, Azin SA, Aeenparast A, Omidvari S, Jahangiri K, Seddighi Z, et al. Self-rated health among Iranians: findings from the Iranian Health Perception Survey (IHPS), Payesh, 2011;10(3):355-363.

28. Mousavi M, Shiani M, Mohammadi MA, Sadjadi H, Tabatabaee F, Assari S. Life satisfaction in Iran; A national representative study. Sci. Res. Essays. 2011 Apr 18;6(8):1839-44.

29. Montazeri A, Omidvari S, Azin A, Aeenparast A, Jahangiri K, Sadighi J, Ebadi M, et al. Happiness among Iranians: findings from the Iranian Health Perception Survey (IHPS). Payesh. 2012;11(4): 467-475.

30. Bonsaksen T, Exploring gender differences in quality of life. Ment Health Rev. 2012;17(1):39-49.

31. Lucas RE, Donnellan MB. Estimating the reliability of single-item life satisfaction measures: Results from four national panel studies. Soc Indic Res. 2012 Feb 1;105(3):323-31. 